\title{
Cotinine Concentrations in Plasma of Smoking Pregnant Women and Their Infants
}

\author{
Patricia E. A. M. Mercelina-Roumans ${ }^{1}$, Hubert Schouten ${ }^{2}$,Johannes M. H. Ubachs ${ }^{1}$ and Jan W. J. van Wersch ${ }^{3}$ \\ 1 Department of Obstetrics and Gynaecology, de Wever Hospital, Heerlen, The Netherlands \\ 2 Department of Methodology and Statistics, University of Limburg, Maastricht, The Netherlands \\ 3 Department of Haematology, De Wever Hospital, Heerlen, The Netherlands
}

Summary: In the Netherlands $30 \%$ of all women of reproductive age are habitual smokers. One third of these women continue to smoke during pregnancy. Tobacco smoke consists of more than 3600 different compounds. One of its chief pharmacologically active ingredients is nicotine of which $60 \%$ is metabolized to cotinine. Cotinine is the best available biochemical marker of nicotine consumption because it is specific for tobacco smoke exposure and it has a relatively long mean $t_{1 / 2}$ of 15 hours.

In the present study nicotine and cotinine concentrations were measured in 25 smoking and 25 non-smoking healthy pregnant women. In all 25 non-smoking pregnant women nicotine and cotinine levels were $<10 \mathrm{mg} / \mathrm{l}$. Light smokers ( $<10$ cigarettes/day) were found to have nicotine blood concentrations $<10 \mathrm{mg} / 1$ and cotinine levels varying between 40 and $99 \mathrm{mg} / \mathrm{l}$. Heavy smokers ( $\geq 10$ cigarettes/day) had nicotine concentrations $<10 \mathrm{mg} / \mathrm{l}$, but high cotinine levels varying from 115 to $199 \mathrm{mg} / \mathrm{l}$.

Cotinine was also determined in 25 neonates of non-smoking mothers and in 34 neonates of smoking mothers. In 9 of these 34 newborns the relationship between maternal and neonatal cotinine concentrations was investigated. Cotinine levels in neonates born to non-smokers and to women who smoked less than 10 cigarettes/day were below the detection limit of $10 \mathrm{mg} / \mathrm{l}$. Cotinine values in neonates whose mothers smoked $\geq 10$ cigarettes/day were significantly higher than in those whose mothers smoked $<10$ cigarettes/day, but significantly lower than in their mothers.

The results of this study confirm that cotinine is more useful than nicotine in discriminating non-smokers, light and heavy smokers. Cotinine concentrations were significantly lower in the neonates than in their mothers, but there was a strong positive linear relationship between maternal and neonatal cotinine concentrations.

\section{Introduction}

In the Netherlands $30 \%$ of all women of reproductive age are habitual smokers. Surveys of smoking during pregnancy have shown that the prevalence of smoking in this group of women is high (1). Several studies have assessed that while approximately $40 \%$ of smokers may reduce their level of tobacco consumption during pregnancy, one third of all pregnant women continue to smoke $(2,3)$. Nicotine dependence is the most powerful driving force for continue the habit (4).

Tobacco smoke consists of more than 3600 different compounds (5) and its composition varies with the type of tobacco and the way it is smoked. The chief pharmacologically active ingredients are nicotine and tar. An average cigarette contains approximately $1 \mathrm{mg}$ nicotine.

Cigarette smoking during pregnancy is associated with a well-documented increase in perinatal mortality and morbidity rates $(6,7)$. Most of the adverse effects of smoking are related to chronic fetal hypoxia arising from decreased uteroplacental perfusion and increased levels of carboxyhaemoglobin in fetal blood (8). These effects are mainly caused by nicotine, tar and carbon monoxide. Nicotine also exerts significant haemodynamic effects in the mother by increasing arterial blood pressure and heart rate (9).

Fifty to ninety percent of nicotine in smoke is absorbed by the smokers and can be detected in the blood shortly after smoking (10). In adults the elimination half-life of nicotine in blood is approximately 120 minutes, and $60 \%$ of the substance is metabolized to cotinine $(11,12)$, of which $10 \%$ is excreted as such in the urine (12). Cotinine is slowly cleared from the body and is primarily eliminated by the liver (13). Renal clearance accounts for about $17 \%$ of total clearance. Because of the low rate of metabolism and renal excretion, the half-life $\left(t_{1 / 2}\right)$ of cotinine is approximately 15 hours $(10-20 \mathrm{~h})(10)$. As a consequence of the long $t_{1 / 2}$ there is relatively little fluctuation in blood concentration throughout the day. Various biochemical procedures have been used to esti- 
mate exposure to tobacco smoke: blood concentrations of nicotine, cotinine, carbon monoxide $(\mathrm{CO})$ carboxyhaemoglobin $(\mathrm{COHb})$ and thiocyanate have been determined. Levels of thiocyanate, $\mathrm{CO}$ and $\mathrm{COHb}$ are easy to determine but may be artificially raised through exposures unrelated to smoking, such as traffic exhaust gases (CO) and diet (thiocyanate) (14).

A few studies have attempted to compare the various biochemical tests. Hill et al. (15) concluded that plasma and serum cotinine are valid indicators of smoke absorption, while $\mathrm{COHb}$ levels correlate well with cigarette smoke inhalation. Pojer et al. (16) reached the same conclusion. Jarvis et al. (14) are of the opinion that measurements of cotinine are best used in discriminating smokers from non-smokers.

While the effects of nicotine on the pregnant mother and her fetus have already been discussed, little is known about the effects of cotinine. Benowitz et al. (11) observed no change in blood pressure, heart rate or skin temperature, effects extremely sensitive to low concentrations of nicotine. Keenan et al. (17) assessed that cotinine has psychoactive properties. Clark et al. (18) found that the pharmacodynamic activity of cotinine is only $1 / 100$ of that of nicotine.

Even less is known about the effect of smoking on the actual concentrations of cotinine in smoking pregnant women and their newborns. For this purpose cotinine levels were measured simultaneously in maternal blood plasma (study group 1) and cord blood plasma (study group 2).

\section{Subjects and Methods}

Nicotine and cotinine concentrations were measured in the venous blood plasma of 25 smoking and 25 non-smoking healthy pregnant women, in the second trimester of their pregnancy. This checkpoint was chosen because Sexton et al. (19) indicated that by the time a smoker reaches her second trimester of pregnancy she will either stop smoking or will continue to smoke until delivery. A second study group consisted of 25 neonates born to non-smoking mothers and 34 neonates born to smoking mothers. In 9 of these cases, the mothers were also investigated, in order to determine the relationship between maternal and neonatal cotinine concentrations. In the second group only cotinine levels were measured. Venous samples were taken because values for venous blood have been published and are available for comparison. Nicotine as well as cotinine levels were determined by gas chromatography (20) nitrogen-phosphorus detection of nicotine and cotinine. The measurements were conducted by the Department of Toxicology, University Hospital, Maastricht, The Netherlands. A Hewlett Packard 5890A gas chromatograph was used. The detection limit for nicotine was $10 \mathrm{mg} / \mathrm{l}$. Duplicity: nicotine $5.6 \% /$ cotinine $3.6 \%$. Reproducibility: nicotine $8.4 \% /$ cotinine $5.3 \%$ The reference ranges for light smokers $(<10$ cigarettes/day): nicotine $<10 \mathrm{mg} / \mathrm{l} /$ cotinine $10-100 \mathrm{mg} / \mathrm{l}$ and heavy smokers ( $\geq 10$ cigarettes/day): nicotine $>10 \mathrm{mg} / \mathrm{l} /$ cotinine $\geq 100 \mathrm{mg} / \mathrm{l}$, are mentioned in table 1 .

Blood samples were drawn between 8.30 and 9.00 a.m., at least one hour after the last cigarette was smoked. Venous blood samples of the newborns were obtained from the clamped umbilical cord immediately after delivery. The samples of their mothers were
Tab. 1 Nicotine and cotinine values in 13 light and 12 heavy smokers

\begin{tabular}{|c|c|c|c|c|c|}
\hline \multirow[t]{2}{*}{$\begin{array}{l}\mathrm{Pa}- \\
\text { tient } \\
\text { No. }\end{array}$} & \multicolumn{2}{|c|}{$\begin{array}{l}\text { Light smokers } \\
\text { (<10 cigarettes/day) } \\
\text { Reference range }\end{array}$} & \multirow[t]{2}{*}{$\begin{array}{l}\mathrm{Pa}- \\
\text { tient } \\
\text { No. }\end{array}$} & \multicolumn{2}{|c|}{$\begin{array}{l}\text { Heavy smokers } \\
\text { ( } \geq 10 \text { cigarettes/day) } \\
\text { Reference range }\end{array}$} \\
\hline & $\begin{array}{l}\text { Nicotine } \\
<10 \mathrm{mg} / \mathrm{l}\end{array}$ & $\begin{array}{l}\text { Cotinine } \\
10- \\
100 \mathrm{mg} / 1\end{array}$ & & $\begin{array}{l}\text { Nicotine } \\
>10 \mathrm{mg} / \mathrm{l}\end{array}$ & $\begin{array}{l}\text { Cotinine } \\
\geq 100 \mathrm{mg} / \mathrm{l}\end{array}$ \\
\hline 1 & $<10$ & 85 & 1. & $<10$ & 119 \\
\hline 2 & $<10$ & 99 & 2. & $<10$ & 115 \\
\hline 3 & $<10$ & 63 & 3. & $<10$ & 126 \\
\hline 4 & $<10$ & 84 & 4. & $<10$ & 152 \\
\hline 5 & $<10$ & 66 & 5. & $<10$ & 124 \\
\hline 6 & $<10$ & 67 & 6. & $<10$ & 127 \\
\hline 7 & $<10$ & 67 & 7. & $<10$ & 135 \\
\hline 8 & $<10$ & 40 & 8. & $<10$ & 184 \\
\hline 9 & $<10$ & 85 & 9. & $<10$ & 150 \\
\hline 10 & $<10$ & 42 & 10. & $<10$ & 198 \\
\hline 11 & $<10$ & 64 & 11. & $<10$ & 199 \\
\hline 12 & $<10$ & 87 & 12. & $<10$ & 132 \\
\hline 13 & $<10$ & 81 & & & \\
\hline
\end{tabular}

drawn during labour, 2-5 hours after the last cigarette was smoked.

The Mann-Whitney-U test was used to compare the differences between the cotinine concentrations in neonates born to smoking and non-smoking mothers.

The Wilcoxon signed rank test was used to test the significance of differences in the plasma cotinine concentration between smoking mothers and their newborns. The Spearman rank correlation coefficient was used to estimate the correlation between maternal and neonatal cotinine concentrations.

\section{Results}

In all 25 non-smoking pregnant women nicotine and cotinine levels were $<10 \mathrm{mg} / \mathrm{l}$. The smoking group consisted of 13 women who reported smoking $<10$ cigarettes/day (light smokers) and 12 women who reported smoking 10 or more cigarettes/day. The light smokers were found to have nicotine blood levels $<10 \mathrm{mg} / \mathrm{l}$ and cotinine levels varying between 40 and $99 \mathrm{mg} / \mathrm{l}$. Heavy smokers had nicotine levels $<10 \mathrm{mg} / \mathrm{l}$, but high cotinine

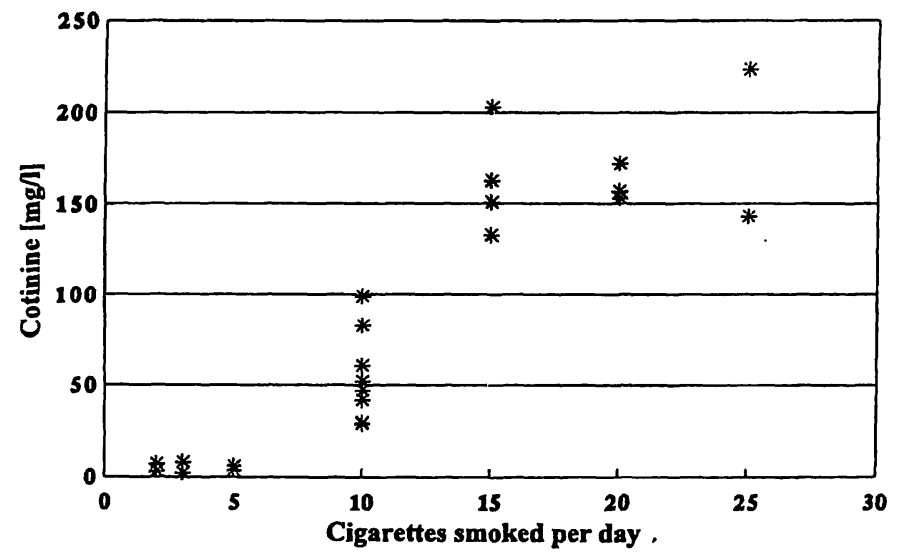

Fig. 1 Cotinine concentrations in umbilical vein plasma in neonates born to smoking mothers. 
Tab. 2 Cotinine concentrations in 9 smoking mothers and their newborns

\begin{tabular}{lccc}
\hline Patient No. & Cigarettes/day & $\begin{array}{l}\text { Neonate } \\
\text { Cotinine } \\
(\mathrm{mg} / \mathrm{l})\end{array}$ & $\begin{array}{l}\text { Mother } \\
\text { Cotinine } \\
(\mathrm{mg} / \mathrm{l})\end{array}$ \\
\hline 1 & 5 & $<10$ & 48 \\
2 & 5 & $<10$ & $<10$ \\
3 & $6-7$ & $<10$ & 65 \\
4 & 10 & $<10$ & 55 \\
5 & 10 & $<10$ & 42 \\
6 & $10-15$ & 67 & 68 \\
7 & $10-15$ & 78 & 82 \\
8 & $17-20$ & 102 & 171 \\
9 & $>20$ & 110 & 173 \\
\hline
\end{tabular}

levels varying from 115 to $199 \mathrm{mg} / \mathrm{l}$. Of the women who reported smoking more than 15 cigarettes/day (heavy smokers), 3 had cotinine values $>175 \mathrm{mg} / \mathrm{l}$.

Cotinine levels in neonates of non-smokers and women who smoked less than 10 cigarettes/day were below the detection limit of $10 \mathrm{mg} / \mathrm{l}$. Figure 1 shows the cotinine concentrations in neonates in relation to their mothers' smoking habits. Cotinine values in neonates whose mothers smoked $\geq 10$ cigarettes/day were significantly higher $(p<0.001)$ than in those whose mothers smoked $<10$ cigarettes/day, but significantly lower than in their mothers $(p<0.01)$. There seems to be a threshold around 10 cigarettes/day. The cotinine concentrations in the 9 smoking mothers and their infants are shown in table 2 . The correlation between cotinine concentrations in maternal and umbilical vein plasma is illustrated in figure 2. The Spearman rank correlation coefficient was 0.912 with a p-value of 0.001 .

\section{Discussion}

The cotinine measurements in our first study group confirm that cotinine is more useful than nicotine for discriminating between non-smokers, light smokers and heavy smokers. This is in accordance with earlier findings $(21-25)$. Nicotine levels in smokers were below the detection limit of $10 \mathrm{mg} / \mathrm{l}$ because blood samples were taken at least one hour after the last cigarette was smoked. In adults the elimination half-life of nicotine in blood is approximately 120 minutes. For comparison with other studies, it is important to state that none of the women in the present study underestimated their smoking habits.

The amount of products of tobacco smoke transmitted to the fetus varies consistently, depending on the proportion of each cigarette consumed, frequency of puffing, depth of inhalation and maternal metabolism $(14,15)$. After birth, the neonate's own metabolism affects the levels and duration of exposure to smoke products. For this reason, cotinine measurements were carried out in the plasma of neonates born to smokers and non-smokers in parallel with measurements in maternal plasma. The results of this study show that cotinine is easily transferred to the neonatal compartment. Cotinine concentrations were significantly lower in the neonates than in their mothers $(p<0.01)$, but there was a strong positive linear relationship between maternal and neonatal cotinine concentrations $\left(r_{s}=0.912, p<0.001\right)$. Donnenfeld et al. (26) found that fetal cotinine concentrations were about $90 \%$ of maternal values throughout gestation. Luck et al. (27) found similar cotinine concentrations in smoking mothers and their neonates.

Cotinine concentrations were below the detection limit of $10 \mathrm{mg} / \mathrm{l}$ in neonates born to non-smoking mothers and in neonates born to mothers who smoked less than 10 cigarettes/day. Infants of mothers who smoked $\geq 10$ cigarettes/day had significantly higher cotinine levels $(p<0.001)$. There seems to be a threshold around 10 cigarettes/day.

Bardy et al. (28) measured tobacco exposure during pregnancy, in order to determine the effects on neonates of maternal smoking. They found a quantitative dose/ effect relationship between tobacco exposure (cotinine concentrations) and a decrease in the gestational age at birth and the size of the neonate. It might be fortuitous that Peacock et al. (29) found a threshold of 13 cigarettes per day for the effect of smoking on birth weight.

In conclusion, cotinine is more useful than nicotine for discriminating between non-smokers, light smokers and heavy smokers. Cotinine, the principal metabolite of nicotine, readily appears in measurable concentrations in the neonate when his/her mother smokes $\geq 10$ cigarettes per day. Cotinine concentrations in neonates are significantly lower than in their mothers, but there is a strong positive linear relationship between cotinine concentrations in the maternal and neonatal compartment.

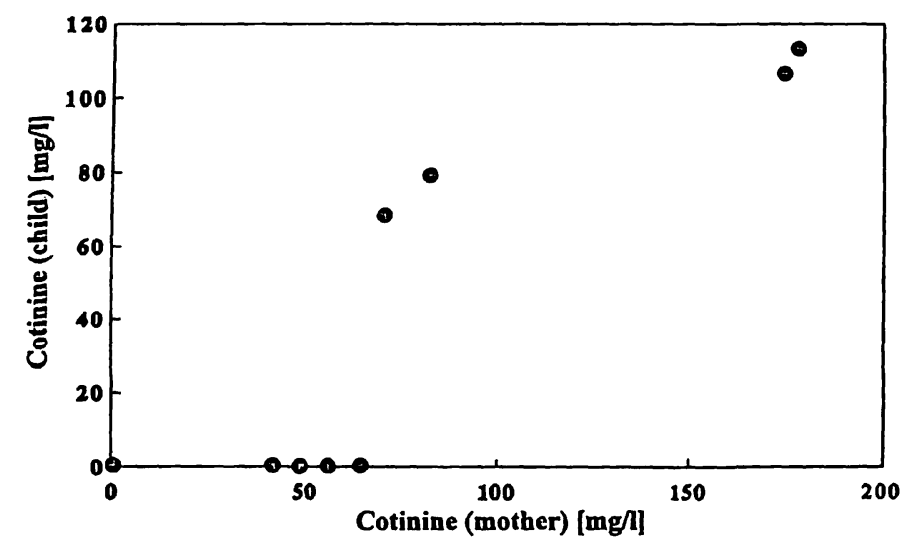

Fig. 2 Correlation between cotinine concentrations (mg/l) in umbilical vein and maternal vein plasma $\left(r_{s}=0.912, p<0.001\right)$. 


\section{References}

1. Baric L, MacArthur C. Health norms in pregnancy. Br J Prev Soc Med 1977: 31:30-8.

2. Cardozo LD, Gibb DM, Studd JW, Cooper DJ. Social and obstetric features associated with smoking in pregnancy. $\mathrm{Br} J$ Obstet Gynaccol 1982; 89:622-7:

3. Rubin PC, Craig GF, Gavin K, Summer D. Prospective survey of use of therapeutic drugs, alcohol, and cigarettes during pregnancy. Br Med J Clin Res Ed 1986; 292:81-3.

4. Gillics PA. Madeley RJ, Power FL. Why do pregnant women smoke? Public Health 1989; 103:337-43.

5. Wynder EL, Hoffman D. Tobacco. In: Schottenfeld D, Faumeni JF, editors. Cancer epidemiology and prevention. New York: Saunders, 1982:277-92.

6. Belch JJ, McArdle BM, Burns P, Lowe GD, Forbes CD. The effects of acute smoking on platelet behaviour, fibrinolysis and haemorheology in habitual smokers. Thromb Haemost 1984; 51:6-8.

7. Allen RA, Kluft C, Brommer EJ. Effect of chronic smoking on fibrinolysis. Arteriosclerosis 1985; 443-50.

S. Lehtovirta $P$, Forss $M$. The acute effect of smoking on intervillous blood flow of the placenta. Br J Obstet Gynaecol 1978; 85:729-31.

9. Quigley ME, Sheehan KL, Wilkes MM, Yen SS. Effects of maternal smoking on circulating catecholamine levels and fetal heart rates. Am J Obstet Gynecol 1979; 133:685-90.

10. Curvall M, Enzell CR. Monitoring absorption by means of determination of nicotine and cotinine. Arch Toxicol Suppl 1986; 9:88- 102

11. Benowitz NL, Jacob P 3d, Jones RT, Rosenberg J. Interindividual variability in the metabolism and cardiovascular effects of nicotine in man. J Pharmacol Exp Ther 1982; 221:368-72.

12. Russell MA, Jarvis M, lyer R, Feyerabend C. Relation of nicotine yield of cigarettes to blood nicotine concentrations in smokers. Br Med J 1980; 280:972-6.

13. Benowitz NL, Kuyt F, Jacob P 3d, Jones RT, Osman AL. Cotinine disposition and effects. Clin Pharmacol Ther 1983; 34:604-11.

14. Jarvis MJ, Tunstall-Pedoe H, Feyerabend C, Vesey C, Saloojee $Y$. Comparison of tests used to distinguish smokers from nonsmokers. Am J Public Health 1987; 77:1435-8.

15. Hill P, Haley NJ, Wynder EL. Cigarette smoking: carboxyhemoglobin, plasma nicotine, cotinine and thiocyanate versus selfreported smoking data and cardiovascular disease. J Chronic Dis 1983: $36: 439-49$.

16. Pojer R, Whitfield JB, Poulos V, Eckhard IF, Richmond R, Hensley WJ. Carboxyhemoglobin, cotinine, and thiocyanate assay compared for distinghuishing smokers from non-smokers. Clin Chem 1984; 30:1377-80.
17. Keenan RM, Hatsukami DK, Pentel PR, Thompson TN, Grillo MA. Pharmacodynamic effects of cotinine in abstinent cigarette smokers. Clin Pharmacol Ther 1994; 55:581-90.

18. Clark MS, Rand MJ, Vanov S. Comparison of pharmacological activity of nicotine and related alkaloids occuring in cigarette smoke. Arch Int Pharmacodyn Ther 1965; 156:363.

19. Sexton M, Hebel JR. A clinical trial of change in maternal smoking and its effect on birth weight. J Am Med Ass 1984; 251:911-5.

20. Jacob P 3d, Wilson M, Benowitz NL. Improved gas chromatographic method for the determination of nicotine and cotinine in biologic fluids. J Chromatogr 1981; 222:61-70.

21. Benowitz NL, Kuyt F, Jacob P 3d, Jones RT, Osman AL. Cotinine disposition and effects. Clin Pharmacol Ther 1983; 34:604-11.

22. Perez-Stable EJ, Benowitz NL, Marin G. Is serum cotinine a better measure of cigarette smoking than self-report? Prev Med 1995; $24: 171-9$.

23. Wald NJ, Idle M, Boreham J, Bailey A. Carbon monoxide in breath in relation to smoking and carboxyhaemoglobin levels. Thorax 1981; 36:366-9.

24. Friedman GD, Siegelaub AB, Seltzer CC, Feldman $R$, Collen MF. Smoking habits and the leukocyte count. Arch Environ Health 1973; 26:137-43.

25. Yarnell JW, Sweetnam PM, Rogers S, Elwood PC, Banton D, Baker IA, et al. Some long term effects of smoking on the haemostatic system: a report from the Caerphilly and Speedwell Collaborative Surveys. J Clin Pathol 1987; 40:909-13.

26. Donnenfeld AE, Pulkkinen A, Palomaki GE, Knight GJ, Haddow JE. Simultaneous fetal and maternal cotinine levels in pregnant women smokers. Am J Obstet Gynecol 1993; 168:781-2.

27. Luck W, Nau H, Hansen R, Steldinger R. Extent of nicotine and cotinine transfer to the human fetus, placenta and amniotic fluid and smoking mothers. Dev Pharmacol Ther 1985; 8:384-95.

28. Bardy AH, Seppälä T, Lillsunde P, Kataja KM, Koskela P, Pikkarainen $\mathrm{J}$, et al. Objectively measured tobacco exposure during pregnancy: neonatal effects and relation to maternal smoking. Br J Obstet Gynaecol 1993; 100:721-6.

29. Peacock JL, Bland JM, Anderson HR, Brooke OG. Cigarette smoking and birthweight: type of cigarette smoked and a possible threshold effect. Int J Epidemiol 1991; 20:405-12.

\section{Received February 7/March 19, 1996}

Corresponding author: Dr. J. W. J. van Wersch, Dept. of Haematology, De Wever Hospital, P.O. Box 4446, NL-6401 CX Heerlen, The Netherlands 